\section{Telomere loss and cancer}

SIR - Hastie et al. speculated ${ }^{1}$ that shortening of chromosome telomeres due to physiological attrition (ageing) may generate tumours. But if the loss or deletion of telomeric sequences due to senescence (or high tissue turnover) were the main factor in tumorigenesis, one would expect a low incidence of tumours in tissues such as those of the central nervous system or bone marrow stroma ${ }^{2}$ normally unable to undergo regeneration. Determination of telomere length in such tissues would represent the only proper falsification context for the above speculation.

Tumours of the central nervous system, whose cells are unable to regenerate, are relatively frequent (overall incidence in the United States being 14,000 cases per year ${ }^{3}$ ). Moreover, most cerebral and spinal cord neoplasms are found in children, which argues against the significance of both ageing and cellular turnover in the loss of telomeric sequences and consequent cancer.

It is, therefore, not surprising (at least for a clinician) that the authors of a paper ${ }^{4}$ from the same research centre as that of Hastie $e t$ al., suggest that, in mice, telomore size is unaffected by repeated somatic division (cellular turnover) and animal's lifespan (ageing). It appears that, in this case, clinical experience would predict that telomere shortening is unlikely significantly to influence carcinogenesis in men and mice.

Notwithstanding the above criticisms, Hastie et al. made an important observation that telomere lengths reflect fairly consistently the past mitotic dynamics of the somatic tissues. This may eventually be of practical help, particularly in the study of subpopulations of haemopoietic stem cells and progenitors. Also, telomere lengths may reflect generation time and cellular dynamics of leukaemic clonogenic cells, thus aiding in the design of therapeutic strategy for individual patients.

G.M. J.JANKovIC M.D. ColO'viC M.D. Petrovic

Institute of Hematology, University Clinical Center, 11.000 Belgrade, ul. Dr Koste Todorovića br. 2, Yugoslavia

HASTIE ET AL. REPLY - We hypothesized that telomere loss may play a part in generating the genetic instability observed in a particular cancer, colorectal carcinoma ${ }^{1}$. Jankovic et al. attribute to us more far-reaching conclusions than we made from our study. Of course, if telomere length were the main and only factor in generating neoplasia (an improbable suggestion) we might expect a low incidence of tumours in tissues such as those of the central nervous system that have low cellular turnover. We agree that if terized by a reduction in $\mathrm{N}_{2} \mathrm{O}$ (ref. 1) and probably in other gases whose source is also in the lower atmosphere (methane, chlorofluorocarbons). barely observable by remote sensors on satellites or balloons. Because limb-sounding sensors observe horizontally through the curved atmosphere, their horizontal resolution is $400 \mathrm{~km}$, which is too large. Their potential vertical resolution is $2-3 \mathrm{~km}$, but, increases below $25 \mathrm{~km}$. telomere reduction does indeed reflect cell turnover, this phenomenon is unlikely to play a role in paediatric tumours and those of the central nervous system. But the fact remains that after lung cancer, the most common cause of death due to cancer in the United Kingdom and the United States remains colorectal cancer; central nervous system tumours are extremely rare by comparison.

We also showed that mouse telomeres are very long even in old animals and concluded that telomere reduction is unlikely to play a role in cancer or ageing in mice ${ }^{5}$. If, as we predict, telomere loss amounts to just four base pairs per somatic cell division, we would not expect to see any measurable reduction in mouse telomeres over a twoyear life span, even if such a reduction were occurring.

We feel Jankovic et al. are on weak footing when they surmise that if telomere loss does not play a role in carcinogenesis in mice, it is unlikely to play such a role in man. Also, at present we cannot rule out dramatic telomere loss in mouse cancers.

We feel our most original and interesting conclusion was that telomere loss may reflect the number of cell divisions in a tissue's history, constituting a type of clock. We are now testing this idea by studying telomere length in a wide range of human tissues, including muscle and brain where cellular turnover is low.

N. D. HASTIE

M. DEMPSTER

M. G. DUNLoP

A. M. THOMPSON

D. K. GREEN

R. C. AlLshire

Medical Research Council,

Human Genetics Unit,

Western General Hospital,

Crewe Road,

Edinburgh EH4 2XU, UK

1. Hastie, N.D. Dempster, M. Dunlop, M.G. Thompson, A.M., Green, D.K. \& Allshire, R.C. Nature 346, 866-868 (1990)

2. Ben-Ishay, Z. et al. Med. Oncol. Tumor Pharmacother. 7 55-59 (1990).

3. DeVita, V.T. Jr., Hellman, S. \& Rosenberg, S.A. Cancer (2nd edn) 1437-1510 (Lippincott, London, 1985)

4. Kipling D. \& Cooke, H.J. Nature 347, 400-402 (1990).

5. Starling, J.A. et al. Nucleic Acids Res. 18, 6881-6888 (1990).

\section{Measuring air from polar vortices}

SIR-Tuck has suggested ${ }^{1}$ that stratospheric air from within the Arctic winter vortex may be transported into mid-latitudes in cells as small as $200 \mathrm{~km}$ horizontally and $3 \mathrm{~km}$ vertically. Because such cells contain large amounts of reactive chlorine ${ }^{2}$, they may be important in the ozone depletion in the Northern Hemisphere winter identified by the report of the International Ozone Trends Panel $^{3}$. Cells of ex-vortex air are also charac-

Unfortunately, such cells are A except in the case of a balloon- A pseudo-in situ balloon-borne limb sounder for high-resolexcept in the case of a balloon- ution measurements of ex-vortex air would subtract signals borne sensor, in practice this is emitted from weak infrared or microwave lines at small degraded by the field of view to angles equally above and below the horizontal ( $A-B)$. Pro5-6 km, again too large. Many vided the atmosphere were horizontally uniform for distan constituents decrease in concen- ces of $150 \mathrm{~km}$, the dashed and dot-dashed beams would tration below 20 or $25 \mathrm{~km}$, which contribute equal signals; the difference signal would origin further degrades the vertical res- ate within the $0.5 \mathrm{~km}$ vertically below the balloon and within olution. Conversely, the resolu- $150 \mathrm{~km}$ horizontally.

tion of measurements of the source gases is improved because their concentration

Because limb-sounders are usually specified for maximum sensitivity, they observe the strongest absorption or emission lines. In the infrared, these frequently saturate at the should be less than $200 \mathrm{~km}$; to achieve a vertical resolution better than $3.5 \mathrm{~km}$, the vertical field of view at the tangent point should be less than $1 \mathrm{~km}$. At the expense of signalto-noise ratio, the vertical resolution could be further improved by oversampling in the vertical plane and subtracting signals in ad- 